\title{
The International Conferences on Law Enforcement and Public Health, a focus for community safety and well-being: Global potential unleashed as LEPH goes annual to North America and Europe
}

\author{
John Nicholas Crofts* and Norman E. Taylor ${ }^{\dagger}$
}

This article is related directly to the recent Law Enforcement Public Health (LEPH) Conference in Toronto, Canada, October 2018

Organized public health is concerned with prevention and effective responses to health threats at the population, as opposed to the individual, level. It has a long and successful history of countering health threats globally, mobilizing multiple professions and sectors-but not, until recently, including the law enforcement sector. This began to change with the recognition of violence, previously solely the province of criminal justice, as a public health issue. The Report of the U.S. Surgeon General in 1979, Healthy People, highlighted control of violent behaviour as a major threat to the health of the American people (US Public Health Service, 1979). A Surgeon General's Workshop on Violence and Public Health in 1985 focused attention on the public health importance of violence and in 1996 the World Health Assembly resolved that "violence is a leading worldwide public health problem," (World Health Assembly, 49, 1996), and the World Health Organization first declared violence to be an urgent matter of the global public health, including violence and victimization associated with crime (Krug, Mercy, Dahlberg \& Zai, 2002). This led to the first solid steps to synergize efforts and interests between public health and law enforcement, steps which were increasingly mirrored in relation to other critical public health issues.

This growing awareness and the whole Law Enforcement Public Health (LEPH) movement gained greater momentum in 2012 with the hosting by the Centre for Law Enforcement and Public Health (CLEPH) of the first international LEPH conference in Melbourne, Australia, in 2012. This was followed by the second conference in 2014 in Amsterdam, The Netherlands, and a return to the Netherlands again in 2016 (see LEPH Conference Links below in the Reference List).

During this period, North American policy makers and practitioners in health, policing, and number of other related fields, grew more and more aware of these imperatives and developments and, by extension, became increasingly interested in the many collaborative practices and supporting evidence these events were helping to generate, study, and publicize. In parallel, similar collaborations were gaining momentum in Canada, after the wide and rapid proliferation of community safety and well-being (CSWB) and collaborative intervention models began there early in the current decade. There was, as a result, some degree of inevitability to the announcement last year that the fourth conference, LEPH2018, would occur in North America, specifically in Toronto, Canada.

As planning for this event moved forward, the Global Law Enforcement and Public Health Association (GLEPHA, https:// gleapha.wildapricot.org/) was further consolidated, now positioned to carry forth with future conferences and other global activities. Canada's Community Safety Knowledge Alliance (CSKA, http://cskacanada.ca) became an active and supportive partner in the Toronto event, with a view to the future as well. It was also decided by the organizers shortly afterward that this multi-sector periodical, CSKA's Journal of CSWB, would become the official peer-reviewed, open-access publication of LEPH for the 2018 event and beyond. This partnership was announced in conjunction with a stepped-up call for related papers in the lead-up to the conference.

\section{Implications Arising from a Toronto Success}

By all accounts, the recent October event in Toronto met and exceeded the expectations of its delegates, whether veterans of the European and Australia experience, or relative newcomers to the global conversation. The growing Canadian commitment to CSWB collaborations was clearly punctuated from the opening by mutually reinforcing, welcoming 
remarks from an Indigenous elder, deputy ministers responsible for policing from two provinces, the executive in charge of Toronto's public health unit, and the Chief of Police of Canada's largest city.

During the three days that followed, many examples of public health, mental health, child protection, housing, corrections, justice, and policing collaborative initiatives were presented and discussed in depth, with each fluidly criss-crossing the social determinants of health and the well-established factors of criminality, victimization and violence, drawing on diverse medical and social science and solid practical evidence, some proven and some merely promising, to date.

Highlights included the plenary sessions, with a range of keynote speakers providing state-of-the-art insight into their own particular fields. The audience for the Plenary session on the second day, for instance, heard about current knowledge in police trauma and wellness from a police officer who has been through the mill and emerged stronger; about the impact of alcohol on Indigenous peoples and exciting, innovative approaches to managing the issue, from a remarkable member of the community; and the importance and impact of local government in bringing partners together and brokering and sustaining partnerships from a representative of the largest local government network in the world. This session was immediately followed by the LEPH Oration, delivered by Sir Michael Marmot, about social justice and health inequity-an utterly engrossing session summarized by its chair as being "for head and for heart".

LEPH Conferences endeavour to provide a mixture of theory and practice to an audience in which policy makers, academics, and practitioners, and people with lived experience from all sectors mix and network. Indeed, the opportunity to move outside your professional bubble and form alliances with - and be inspired by-people from other sectors facing the same issues is one of the best parts of this conference. The Marketplace of Ideas has become an integral part of the LEPH conferences, offering longer sessions with smaller audiences in which innovative programs are showcased and shared with others facing similar issues.

GLEPHA convened a networking meeting prior to the LEPH2018 conference, a show-and-tell meeting of agencies and networks working in this intersectoral space between law enforcement and public health. This pre-conference networking meeting involved 15 agencies and networks from around the globe, an indication of how broad the LEPH movement is becoming.

\section{Our Call to Action}

We are pleased to note that five of the eight features in this current issue of the Journal derive from this nascent LEPHCSWB partnership. With several more excellent features already in the queue, ranging from Original Research to Social Innovation Narratives and Commentaries, we anticipate continuing this pattern across several more issues throughout 2019. We also recognize there are many other presenters, panelists, participants, and observers for whom the timing may have been too tight to commit to publishing in conjunction with the event itself.

We encourage those authors to help us keep up the momentum and the dialogue, and our Section Editors look forward to receiving and reviewing more features in the weeks and months ahead. The Toronto event drew a whole new audience from across North America and beyond. Through this Journal and others, a new global space for collaboration and knowledge exchange is opening for us all to share in our learning and our diverse applications of LEPH and CSWB innovation and much-needed solutions.

\section{Looking Ahead to Edinburgh}

Planning is already underway for the LEPH2019 Conference, scheduled for October 20-23 in Edinburgh, Scotland. It may be somewhat poetic for Canadian CSWB practitioners who are able to join this return to Scotland, since the well-documented genesis of CSWB here in Canada arose from a 2010 field study there, led out of Prince Albert, SK (McFee \& Taylor 2014).

For all delegates world-wide, Edinburgh promises another opportunity to learn about, share, and expand upon LEPH and CSWB practices, as well as to further strengthen the research and evidence base in support of collaborative solutions. Scotland is an acknowledged world leader in innovative and collaborative approaches to complex issues, especially in the Glasgow approach to gangs and gang violence which has inspired much of the rest of the world, as well as for its move to become the first "ACE-aware nation" (Adverse Childhood Experience). LEPH2019 will focus on 'Collaborative Leadership', and feature the same key themes as previous LEPH conferences, including domestic and gender-based violence, mental health crises, police and other first responder well-being, alcohol and other drugs, trauma and catastrophes. The 2019 conference will also build on the experience of previous conferences, and the growing LEPH movement to examine other complex public health and safety issues.

The Global LEPH Association is developing a range of Special Interest Groups, each looking to hold its own pre-conference satellite, as has been done in previous conferences. For Edinburgh, those foreshadowed include law enforcement and mental health; police, drugs, and harm reduction (organized by the LE and HIV Network); education in LEPH; and police well-being. These pre-conference meetings provide an opportunity to dig deeper into particular subjects and to produce concrete outcomes, before joining the main conference.

The now annual LEPH conferences will continue to provide these multiple opportunities for networking, information and experience sharing, and alliance building-in strong recognition that there is currently too much in the way of division in society and in our responses to social issues, and that future success in tackling complex and divisive issues lies in these alliances. The Edinburgh LEPH conference will carry on and build on this new tradition, bringing us all together. We look forward to seeing you there!

\section{CONFLICT OF INTEREST DISCLOSURES}

The authors declare there are no conflicts of interest connected to the submission of this article.

\section{AUTHOR AFFILIATIONS}

*Section Editor, Services; ${ }^{\dagger}$ Editor-in-Chief, Journal of Community Safety and Well-Being. 


\section{REFERENCES}

Krug, E. G., Mercy, J. A., Dahlberg, L. L. \& Zwi, A. B. (2002). The world report on violence and health. The Lancet, 360(9339), 1083-1088.

Centre for Law Enforcement \& Public Health (CLEPH). Melbourne, Australia. Various LEPH Conference Links:

LEPH2012, Melbourne, Australia, 11-14 November. Available from: https:// cleph.com.au/index.php/events/leph2012-melbourne

LEPH2O14, Amsterdam, The Netherlands, 5-8 October. Available from: hitps:// cleph.com.au/index.php/events/leph2014-amsterdam

LEPH2016, Amsterdam, The Netherlands, 2-5 October. Available from: http:// www.leph2016.com/

LEPH2018, Toronto, Canada, 21-24 October. Available from: https://leph2018toronto.com/
LEPH2019, Edinburgh, Scotland, 20-23 October. Available from: https:// leph2019edinburgh.com/

McFee, D. R. \& Taylor, N. E. (2014). The Prince Albert Hub and the emergence of collaborative risk-driven community safety In Change and Innovation in Canadian Policing. Canadian Police College Discussion Paper Series. Ottawa, ON: Canadian Police College.

US Public Health Service (1979). US Department of Health, Education, and Welfare. Healthy people: The Surgeon General's report on health promotion and disease prevention. Washington, DC: US Government Printing Office; 1979.

World Health Assembly, 49. (1996). Prevention of violence: public health priority. Geneva, Switzerland: World Health Organization. Available from: http://www.who.int/iris/handle/10665/179463 